\title{
Ecology, Phylogeny, and Potential Nutritional and Medicinal Value of a Rare White "Maitake" Collected in a Mediterranean Forest
}

\author{
Maria Letizia Gargano ${ }^{1}\left(\mathbb{D}\right.$, Georgios I. Zervakis ${ }^{2}{ }^{\oplus}$, Omoanghe S. Isikhuemhen ${ }^{3}$, \\ Giuseppe Venturella $\left.{ }^{4}{ }^{(}\right)$, Roberta Calvo ${ }^{4, *}$, Anna Giammanco ${ }^{5}$, Teresa Fasciana ${ }^{5}$ and \\ Valeria Ferraro ${ }^{4}$ \\ 1 Department of Agricultural and Environmental Science, University of Bari Aldo Moro, Via Amendola 165/A, \\ I-70126 Bari, Italy; marialetizia.gargano@uniba.it \\ 2 Laboratory of General and Agricultural Microbiology, Agricultural University of Athens, 11855 Athens, \\ Greece; zervakis@aua.gr \\ 3 Mushroom Biology and Fungal Biotechnology Laboratory, Department of Natural Resource \& \\ Environmental Design, North Carolina A\&T State University, Greensboro, NC 27411, USA; \\ omon.isi@fungibiotech.com \\ 4 Department of Agricultural, Food and Forest Sciences, University of Palermo, Viale delle Scienze, Bldg. 5, \\ I-90128 Palermo, Italy; giuseppe.venturella@unipa.it (G.V.); valeria.ferraro@unipa.it (V.F.) \\ 5 Department of Health Promotion, Mother and Child Care, Internal Medicine and Medical Specialities, \\ University of Palermo, 90127 Palermo, Italy; anna.giammanco@unipa.it (A.G.); teresa.fasciana@unipa.it (T.F.) \\ * Correspondence: roberta.calvo@unipa.it; Tel.: +39-349-090-6252
}

Received: 4 May 2020; Accepted: 4 June 2020; Published: 8 June 2020

\begin{abstract}
Albino Grifola frondosa (Dicks.) Gray "maitake" mushrooms (described as G. albicans Imazeki and then placed in synonymy with $G$. frondosa) are particularly rare, and the few pertinent records are not treated in scientific publications. A field investigation carried out in Sicily (Italy) led to the collection of an unusual white Grifola specimen at the base of a living tree of Quercus pubescens Willd. s.l. The outcome of sequencing the internal transcribed spacer (ITS) region of nuclear ribosomal DNA (nrDNA) indicated that it belongs to G. frondosa and provided an insight to the phylogenetic relationships within the genus. The results of nutritional composition analysis showed that the albino basidioma possesses relatively high contents of $\mathrm{Ca}, \mathrm{Fe}, \mathrm{K}$, and $\mathrm{Cu}$ and is rather low in $\mathrm{Na}$ when compared with literature data on edible mushrooms. Vitamin $\left(\mathrm{B}_{1}, \mathrm{~B}_{2}, \mathrm{~B}_{3}, \mathrm{~B}_{5}, \mathrm{~B}_{9}\right.$, and $\mathrm{D}_{2}$ ) contents ranged from 0.15 to $3.89 \mathrm{mg}$ per $100 \mathrm{~g}$ of mushroom dry weight. The cold-water extract of this specimen was effective at inhibiting the growth of Staphylococcus epidermidis ATCC 12228 and Pseudomonas aeruginosa ATCC 15442 at the maximum screening concentration of 50\% v/v. In addition, the extract slowed down the ability of Staphylococcus aureus ATCC 43300 to form biofilms. According to data hereby reported, the albino G. frondosa is a culinary-medicinal mushroom with a promising exploitation potential.
\end{abstract}

Keywords: Grifola frondosa; fungal diversity; Mediterranean forest; medicinal mushroom; bioprospecting; ITS rDNA; phylogenetics; basidiomycete; polypore fungus; Quercus pubescens

\section{Introduction}

The family Grifolaceae Jülich (Polyporales, Basidiomycota) comprises only the genus Grifola Gray [1], which consists of nine species according to Index Fungorum. Grifola frondosa (Dicks) Gray includes several forms and varieties, such as G. frondosa f. frondosa (Dicks.) Gray, G. frondosa f. intybacea (Fr.) Pilát, G. frondosa var. frondosa (Dicks.) Gray, and G. frondosa var. intybacea (Fr.) Cetto, 
while G. intybacea (Fr.) Imazeki is considered as a synonym. The culinary-medicinal mushroom G. frondosa, widely known as "maitake", is a white-rot polypore associated primarily with deciduous trees of different genera (Quercus L., Acer L., Carpinus L., Castanea Mill., Fagus L., Ulmus L.) while it appears more rarely on conifers. This species is distributed in temperate regions of North America, Europe, and Asia (Japan and China) [2]. Albino maitake mushrooms (described as G. albicans by Imazeki in 1943 [3] and then placed in synonymy with G. frondosa) are quite rare and the few available pertinent records do not appear in scientific publications. Only recently, Kawaguchi et al. [4,5] reported on melanin biosynthesis in G. frondosa and suggested that the albino mutation is caused by a single base deletion in the coding region of the tyrosinase 2 (tyr2) gene. It is noteworthy that white strains of G. frondosa are much sought after since they can be used for culinary purposes without the unwanted dark brown pigment resulting from processing the common form of this mushroom [4].

Edible mushrooms are widely acknowledged for their nutritional and medicinal properties [6]; however, their potential market is still far from being fully developed considering that there is a high consumer demand. Consequently, the private sector is eager to generate new relevant products. In the frame of a research project aiming at collecting mushrooms with bioprospecting potential, a field investigation carried out in Sicily (Italy) led to the collection of an unusual Grifola basidioma of white color and considerable weight (ca. $7 \mathrm{~kg}$ ). The objective of the present work was to provide morphological, molecular/phylogenetic, and ecological data about this rare albino Grifola specimen. Information on the nutritional value and antimicrobial activity is also reported.

\section{Materials and Methods}

\subsection{Sample Collection, Habitat Details, and Evaluation of Morphological Characters}

Research carried out in forest ecosystems in Sicily (Italy) led to the collection of a single albino Grifola basidioma found at the base of a monumental downy oak tree (Quercus pubescens Willd. s.1.), 10 January 2016, Castelbuono, Madonie Regional Park (province of Palermo, Sicily), $800 \mathrm{~m}$ a.s.l., $37^{\circ} 54^{\prime} 48^{\prime \prime} \mathrm{N}, 14^{\circ} 04^{\prime} 41^{\prime \prime}$ E. In Castelbuono, summers are rather brief, hot, and dry, with clear skies and condensation often appearing in the late afternoon, while winters are long, cold, rainy, and windy. Annual temperature ranges from 7 to $29^{\circ} \mathrm{C}$ (rarely below $4{ }^{\circ} \mathrm{C}$ or above $32{ }^{\circ} \mathrm{C}$ ) while the average value is $15.8^{\circ} \mathrm{C}$. The average annual rainfall is $515 \mathrm{~mm}$. In January, the month when the specimen under study was harvested, the average temperature is $8.9^{\circ} \mathrm{C}$, and the respective maximum and minimum values are 11.5 and $6.3^{\circ} \mathrm{C}$; the rainfall is $67 \mathrm{~mm}$. The forest is characterized by evergreen and deciduous oak vegetation with a prevalence of Quercus ilex L. and Q. pubescens Willd. s.l. In the upper part of the mountain, the vegetation is characterized by mixed woods of oaks, Fagus sylvatica L. and Ilex aquifolium L. The specimen was transferred to the Department of Agricultural, Food, and Forest Sciences (SAAF) of the University of Palermo, and stored at $<4{ }^{\circ} \mathrm{C}$ for up to $24 \mathrm{~h}$ prior to morphological examination, which was carried out according to Bernicchia [7]. Observations on macromorphological characters (pileus, cuticle, pores, stipe, context, etc.) were performed on fresh material, while microscopic characters (hyphal system, generative hyphae, basidia, sterigmata, cystidia, cystidioles, and basidiospores) were studied by using $3 \%$ potassium hydroxide and ammoniacal Red Congo. In addition, the reaction of the flesh to iodine-potassium iodide, potassium hydroxide, and iron salts was also evaluated.

\subsection{Establishment of Pure Cultures and Mushroom Cultivation Trials}

The collected basidioma was dried and then deposited in the Herbarium of the Department of Agricultural, Food, and Forest Sciences (SAAF 450). Prior to this, a piece of pseudo-tissue was removed from the fresh specimen, placed on potato dextrose agar (PDA) in Petri dishes under aseptic conditions, and incubated for 15 days at $25 \pm 2{ }^{\circ} \mathrm{C}$. The established pure culture was stored in the Mycotheca of the Herbarium SAF (SAF 323), and it was subsequently used for the inoculation of mushroom cultivation substrates composed of either holm oak (Quercus ilex L.) or chestnut (Castanea sativa Miller) 
wood residues. The former (holm oak wood shavings) was filled in plastic bottles (volume: $1 \mathrm{~L} \mathrm{each}$ ), while the latter (chestnut wood chips of ca. $2-3 \mathrm{~cm}$ and sawdust) was filled in plastic bags (volume: $6 \mathrm{~L}$ each) after their moisture content was adjusted to $50-60 \%$; in both cases, non-hydrophilic cotton filters were used to allow air exchange. Sterilization was performed twice at $120^{\circ} \mathrm{C}, 1.1 \mathrm{Atm}$ for $20 \mathrm{~min}$ with a 24-h interval between each cycle. After the final cooling, substrates were inoculated using actively growing mycelium and incubation was carried out at $25^{\circ} \mathrm{C}$ in the dark.

\subsection{DNA Extraction, PCR Amplification, and Sequencing}

Total genomic DNA was extracted from the herbarium specimen using the Nucleospin Plant II DNA kit (Macherey and Nagel, Düren, Germany) following the manufacturer's protocol. The internal transcribed spacer (ITS) region of nuclear ribosomal DNA (nrDNA) was amplified using the primer combination ITS1/ITS4 [8]. Polymerase chain reactions (PCRs) were performed in $50 \mu \mathrm{L}$ containing $50 \mathrm{ng}$ DNA template, $0.25 \mu \mathrm{M}$ of each primer, $0.2 \mathrm{mM}$ of each dNTP, $1 \times$ HiFi Buffer (Takara BIO INC., Shiga, Japan), and 1 U HiFi Taq DNA polymerase (Takara BIO INC., Shiga, Japan). Conditions for PCR amplification were as follows: $94{ }^{\circ} \mathrm{C}$ for $5 \mathrm{~min}$, followed by 35 cycles of $94{ }^{\circ} \mathrm{C}$ for $30 \mathrm{~s}, 50{ }^{\circ} \mathrm{C}$ for $30 \mathrm{~s}$ and $72{ }^{\circ} \mathrm{C}$ for $1 \mathrm{~min}$, and a final extension at $72{ }^{\circ} \mathrm{C}$ for $10 \mathrm{~min}$.

PCR products were purified using an Invitrogen PureLink kit (Thermo Fisher Scientific, Seoul, Korea) and were submitted for sequencing to CeMIA S.A. (Larissa, Greece). The resulting chromatograms were proofread, and the sequence generated was deposited in GenBank under the accession number MN944407.

\subsection{Phylogenetic Analysis of Sequence Data}

In addition to the biological material examined in this study, 53 additional ITS sequences were included in the phylogenetic analysis; 38 of them representing other Grifola Spp., i.e., all available sequences of G. colensoi (Berk.) G. Cunn., G. gargal Singer, and G. sordulenta (Mont.) Singer, and the rest corresponding to two other species used as outgroups, i.e., Polyporus umbellatus (Pers.) Fr. (syn. Grifola umbellata (Pers.) Pilát) and Rhodonia placenta (Fr.) Niemelä, K.H. Larss. \& Schigel (syn. Oligoporus placentus (Fr.) Gilb. \& Ryvarden). Sequence alignment was performed through the aid of the Clustal Omega software (https://www.ebi.ac.uk/Tools/msa/clustalo/); alignments were inspected and manually adjusted at misaligned sites using MEGA X (Pennsylvania State University, State College, PA, USA) [9].

Phylogenetic relationships were inferred by using the maximum likelihood (ML) method based on the Kimura 2-parameter model [10]. Initial tree(s) for the heuristic search were obtained automatically by applying the Neighbor-Join and BioNJ algorithms to a matrix of pairwise distances estimated using the maximum composite likelihood (MCL) approach, and then selecting the topology with the superior log likelihood value. Phylogenetic analysis was conducted in MEGA X [9].

\subsection{Evaluation of Nutritional Value and Determination of Antimicrobial Activity}

The powder resulting after freeze-drying part of the collected basidioma was also subjected to analysis for the evaluation of the nutritional value (proximate composition, and content in elements and vitamins) according to standard methodologies reported by Palazzolo et al. [11], AOAC [12], Thompson et al. [13], and Loewus [14].

With regard to the antibacterial properties, the study initially included the evaluation of the activity of the lyophilized powder deriving from the basidioma against four Gram-positive and Gram-negative bacteria strains: Staphylococcus aureus ATCC 25923, S. epidermidis ATCC 12228, Pseudomonas aeruginosa ATCC 15442, and Escherichia coli ATCC 25922. Tryptic soy broth (Sigma-Aldrich, Darmstadt, Germany) containing glucose $(2 \% w / v)$ or Mueller Hinton (Sigma-Aldrich, Darmstadt, Germany) was used as growth media. The lyophilized sample $(3 \mathrm{~g})$ was placed in a beaker with $200 \mathrm{~mL}$ of demineralized water, and then stored at $-20^{\circ} \mathrm{C}$. 
The minimum inhibitory concentration (MIC) was determined in a Minisart syringe with a $2.5-\mu \mathrm{m}$ cellulose acetate filter by preparing solutions in vitro at increasing concentrations, incubating them with separate lots of cultivated bacteria, and measuring the results using agar dilutions. In addition, the effect of extract obtained from the basidioma powder was examined in respect to the biofilm produced by strains of $S$. aureus ATCC 43300, Enterococcus faecalis ATCC 29212, P. aeruginosa ATCC 27853, E. coli ATCC 25922, and Klebsiella pneumoniae ATCC 700603.

The bacterial strains were inoculated in Trypticase ${ }^{\mathrm{TM}}$ Soy Agar (BBL ${ }^{\mathrm{TM}}$; Becton, Dickinson and Company, Sparks, MD, USA) media and incubated at $37^{\circ} \mathrm{C}$ for $24 \mathrm{~h}$. In total, $100 \mu \mathrm{L}$ of overnight grown culture (0.5 McFarland in tryptose broth, BT) was added in a sterile 96-well flat bottom microtiter plate (Biosigma S.r.l. Dominique Dutscher Group, Brumath, France). The negative control was composed by BT medium only; to demonstrate biofilm production, excess bacterial suspension was removed. Subsequently, the extract from the basidioma powder $(25 \% v / v)$ was re-suspended in BT, $100 \mu \mathrm{L}$ were added in the wells, and the cultures were incubated at $37^{\circ} \mathrm{C}$ for $24 \mathrm{~h}$. Finally, the biofilm was stained with crystal violet dissolved in ethanol $(0.5 \% w / v)$. The optical density was measured at $540 \mathrm{~nm}$ (Spectrophotometer Multiskan Go; Thermo Fisher Scientific, Waltham, MA, USA). The experiment was conducted in triplicate $[15,16]$.

\section{Results and Discussion}

\subsection{Morphological Description of the G. frondosa Specimen and Cultivation Tests}

Basidioma is composed of multiple pilei in the form of a rosette, sharing a branched stem-like structure (Figure 1a). Individual pilei were found to be more or less fan-shaped or deltoid, entirely white and yellowing with age, and finely velvety or bald, with wavy margins, 4 to $10 \mathrm{~cm}$ wide and 5 to $10 \mathrm{~mm}$ thick. The pore surface was shown to be white, staining yellowish when ripe, 2 to $3 \mathrm{~mm}$ deep, and irregular, and varying in shape from round to elongated (Figure 1b); it is slightly decurrent to the stipe. The stipe structure was found to be branched, whitish, tough, and often off-center. The flesh was firm, white, and unchanging when sliced. The odor and taste were found to be mild and pleasant, although less so when decaying or acrid. The chemical reaction of flesh to iodine-potassium iodide and potassium hydroxide was negative. The iron salts reaction on the pileus and flesh was negative. Basidiospores, slightly reduced when compared to the brown maitake $(5-7 \times 3.2 \mu \mathrm{m})$, were found to be broadly ellipsoidal, smooth, 5.0-7.0 $\times 3.2-4.0 \mu \mathrm{m}$, slightly narrower than those of the brown maitake, and inamyloid. Basidia were 25-30 × 6-8 $\mu \mathrm{m}$; clavate; and 4-sterigmata (Figure 2a). Clamp connections were found to be present on generative hyphae but are rare or absent on skeletal hyphae. Hymenial cystidia and cystidioles were absent. The hyphal system is dimitic, and the spore print white. Sterigmata were found to be up to $6 \mu \mathrm{m} \mathrm{long}$, and robust, with a base diameter up to $1.6 \mu \mathrm{m}$ (Table 1). Relevant information referring to the description of common brown form $[7,17]$ is included in Table 1 . It should be mentioned that the length of the sterigmata and the diameter of their base were not reported by Ryvarden [17], while Bernicchia [7] stated that sterigmata appear "thin and very divaricate".

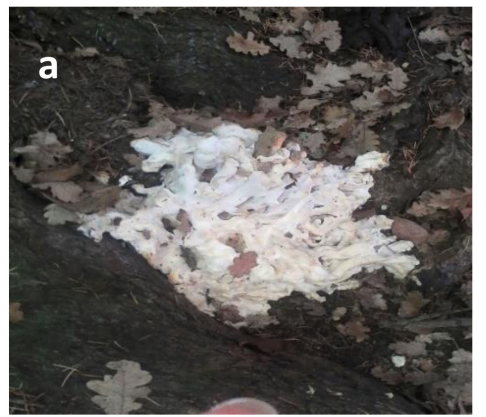

Figure 1. The albino maitake specimen stereomicroscope (scale bar $=1 \mathrm{~mm}$ ).

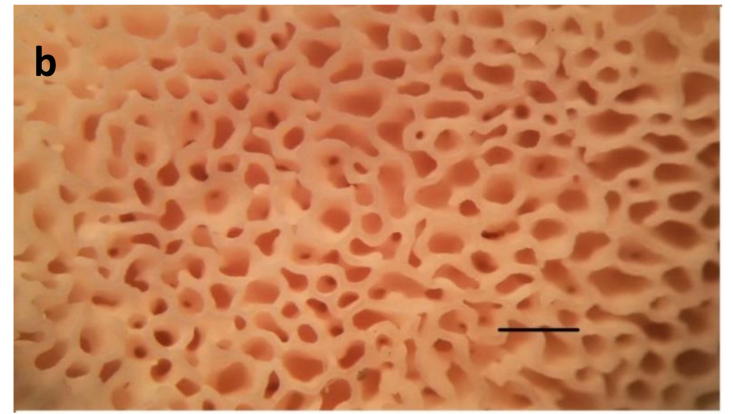
(a) Basidioma in situ; (b) Pore surface under the 

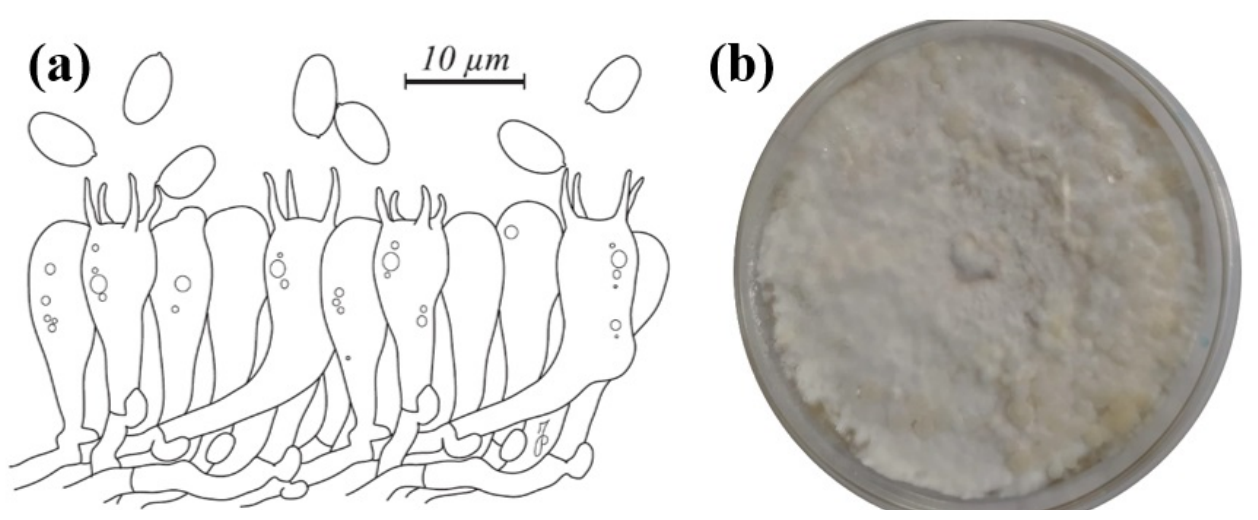

Figure 2. (a) Microscopic features (basidia and spores) of albino maitake. (b) Pure culture isolated from fresh basidioma.

Table 1. Main macro- and micromorphological features of brown $[7,17]$ and albino (this study) forms of maitake.

\begin{tabular}{|c|c|c|}
\hline Descriptive Characters & Brown Form & Albino Form \\
\hline Habit & Cluster of pilei & Cluster of pilei \\
\hline Pileus & Irregular, wrinkled, flat and uneven & Fan-shaped or deltoid \\
\hline Stipe & Whitish & Whitish \\
\hline Tubules & Short, thick, whitish & Short, thick, whitish \\
\hline Pores & $\begin{array}{l}\text { Very small, then angular and wider } \\
\text { Whitish and fleshy, with numerous }\end{array}$ & Round to elongated, slightly decurrent to the stipe \\
\hline Stem & $\begin{array}{l}\text { flattened branches and bifurcations that } \\
\text { end in a fan-shaped pileus }\end{array}$ & Structure branched, whitish, tough, often off-center \\
\hline Flesh & $\begin{array}{c}\text { White, immutable, tenacious especially } \\
\text { towards the base, fragile towards } \\
\text { the pileus }\end{array}$ & Firm, white, unchanging when sliced \\
\hline Smell & Penetrating, intense then nauseating & $\begin{array}{l}\text { Mild and pleasant, unpleasant or acrid } \\
\text { when decaying }\end{array}$ \\
\hline Taste & Pleasant and delicate & $\begin{array}{l}\text { Mild and pleasant, unpleasant or acrid } \\
\text { when decaying }\end{array}$ \\
\hline Basidiospores & Ellipsoidal, $5.0-6.5 \times 3.5-5.0 \mu \mathrm{m}$ & Broadly ellipsoidal, smooth, $5.0-7.0 \times 3.2-4.0 \mu \mathrm{m}$ \\
\hline Basidia & $23-30 \times 5-8 \mu \mathrm{m}$; clavate; 4 -sterigmata & $25-30 \times 6-8 \mu \mathrm{m} ;$ clavate; 4 -sterigmata \\
\hline Hyphal system & Dimitic with clamp connections & Dimitic with clamp connections \\
\hline Habitat & $\begin{array}{l}\text { At the base of hardwoods, particularly } \\
\text { chestnut and oak trees }\end{array}$ & At the base of oak trees \\
\hline Period of fructification & Late August to October & December to January \\
\hline
\end{tabular}

Mycelium growth was very slow in the pure cultures established, and the surface of the Petri dish (diameter $90 \mathrm{~mm}$ ) was completely overgrown in 30 days. The colony was found to be slightly floccose and flat, with dense white hyphae without any zonation and with a filiform margin (Figure 2b). Regarding the cultivation tests performed either in holm oak or in chestnut-based substrates, colonization was slow and ca. two months elapsed before they were completely overgrown by mycelium. At this time, a few primordia were formed on the substrate surface, which, however, failed to produce fully developed basidiomata.

\subsection{Phylogenetic Analysis}

The main objective of the molecular analysis was to identify the biological material under examination (albino maitake). Following BLAST, the sequence (MN944407) from our specimen showed high identity ( $>99 \%$ ) to several other sequences deposited as G. frondosa in GenBank. The generated ML trees had similar topologies, and only the tree with the highest log likelihood (-7662.14) was selected to be presented (Figure 3). 


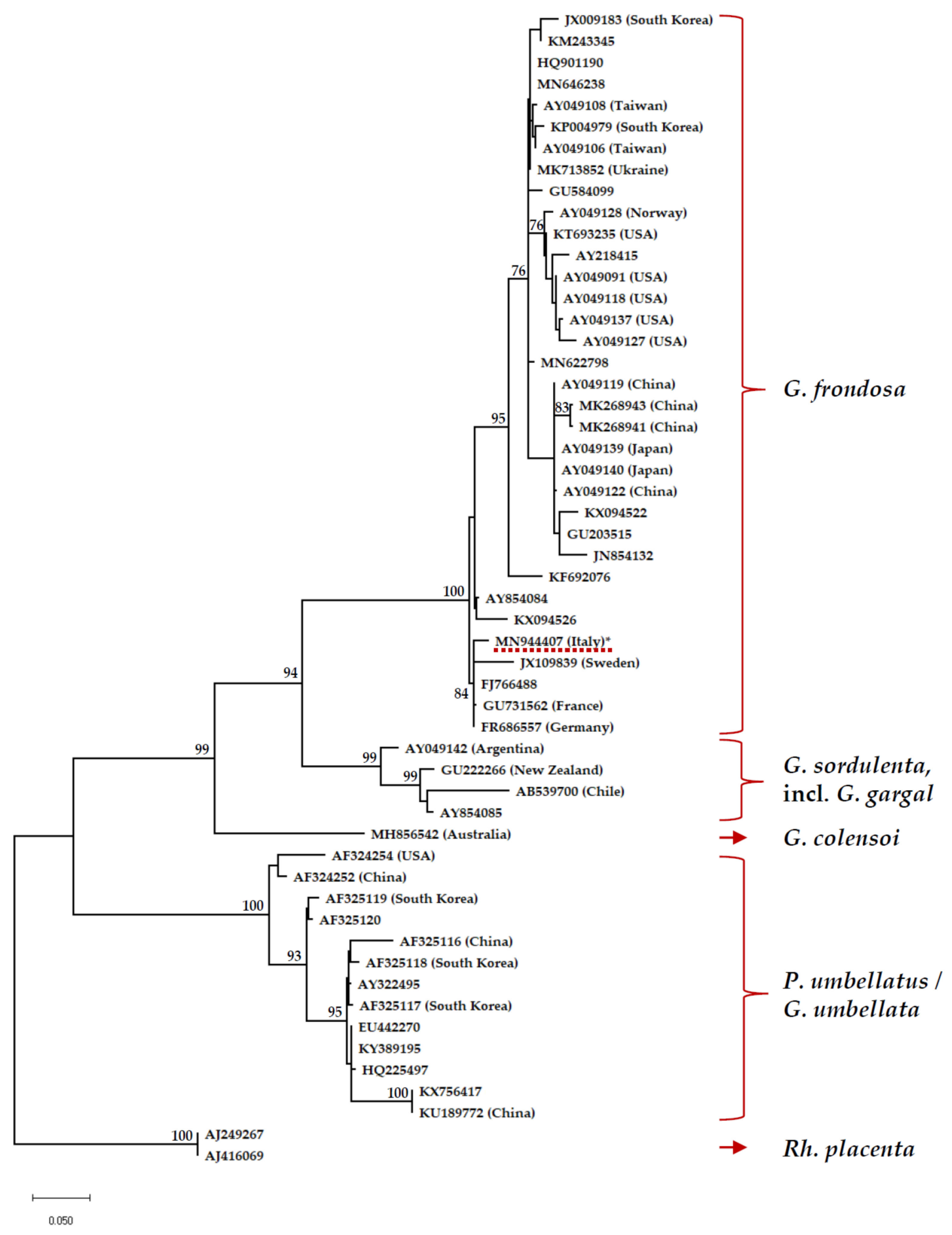

Figure 3. Maximum likelihood tree produced on the basis of ITS (internal transcribed spacer) sequence analysis presenting the phylogenetic position of the albino G. frondosa specimen (underlined in red and marked with an asterisk) among members of the genus Grifola; GenBank accession numbers are quoted together with information of their geographic origin (when available). Sequences of Polyporus umbellatus (syn. G. umbellata) and Rhodonia placenta were used as outgroups. The percentage of trees in which the associated taxa clustered together is shown next to the branches when $\geq 70 \%$ (ML bootstrap support values derived from a total of 1000 replicates). The tree is drawn to scale, with branch lengths measured as the number of substitutions per site. 
To the best of our knowledge, the sequence obtained in this study is the only one available from an albino Grifola specimen. The outcome of the phylogenetic analysis revealed that the albino maitake clusters within the $G$. frondosa terminal clade, which receives high bootstrap support (100\%), and forms a subgroup (84\%) together with other sequences from material collected in Europe; the rest of the G. frondosa sequences derive almost exclusively from east Asia (China, Japan, South Korea, Taiwan) and the USA. Although this subgroup could represent a distinct taxonomic entity, the information generated from our work (through the examination of one basidioma and the use of a single marker only) does not allow such inferences, at least before additional specimens are included and analyzed in the frame of a multigene approach. However, it is noteworthy that $G$. frondosa sequences from Asian and eastern North American isolates were separated through the use of a partial beta-tubulin gene and ITS [18]. G. frondosa forms a sister group to G. sordulenta (94\%). The latter is highly supported (99\%) and consists of three sequences under this name and one representing G. gargal (AB539700). Hence, the distinct taxonomic position of the latter is dubious by examining the ITS marker alone. Of interest was also the position of the sole G. colensoi sequence available (MH856542; this species is known so far from Australia and New Zealand only), which appears to be quite distant from the rest of the material placed in the genus Grifola. Lastly, sequences deposited either as G. umbellata or P. umbelatus form a distinct highly supported group $(100 \%)$, which is well separated from the clade corresponding to Grifola Spp. To the best of our knowledge, the sequence generated in the frame of this work is the first one deriving from an albino G. frondosa specimen.

\subsection{Mushroom Proximate Composition and Content in Elements and Vitamins}

In the frame of this work, it was not possible to analyze (and hence directly compare to our albino specimen) the composition of wild basidiomata of brown maitake since they were not available during the period of the study, this species being very rare in Sicily. On the other hand, only limited literature data are available referring to the chemical composition and vitamin contents in cultivated G. frondosa $[19,20]$; the respective values reported-apart from a few exceptions-are considerably lower than those found in the white maitake. However, such information should be evaluated with care since it is known that the nature of the cultivation substrate could considerably affect the mushroom content [21,22]. Similarly, metal accumulation in wild edible mushrooms was found to be influenced by various factors, including the species, the available concentration of elements in soil substrates, the substrates' properties (e.g., $\mathrm{pH}$, organic matter content), the antagonistic and/or synergistic effects among elements, and the concentration of other elements in mushrooms [23-26].

The results of the proximate composition analysis of the albino maitake showed rather low values of protein, fat, and carbohydrate contents (Table 2), while the calorie content was $35.84 \mathrm{kcal} \cdot 100 \mathrm{~g}^{-1}$. In addition, element analysis showed that this specimen presents relatively high contents in $\mathrm{Ca}, \mathrm{Fe}, \mathrm{K}$, and $\mathrm{Cu}$, and is rather low in Na (Table 2). The Ca content is higher than in some baby foods, such as oatmeal and whole milk, as well as ham, cream, spread cheese, white chocolate, and others [27]. The content in Fe is considerably higher than in most other foods; it is noteworthy that dried thyme (i.e., one of the richest foods in Fe) contains about $50 \mathrm{mg}$ less Fe per $100 \mathrm{~g}$ when compared to the albino G. frondosa. The K content in albino maitake is lower only to that of cremor tartar and much higher than that of dried spirulina algae [27], while the Na content is lower than that of miso soup and baking powder [27]. The $\mathrm{Cu}$ content of albino maitake is higher than most foods, including dark chocolate, oysters, liver, and lobster [27]. 
Table 2. Outcome of proximate composition analysis (\% for nitrogen, proteins, fats, carbohydrates, and ash), and content in elements and vitamins (mg.100 g $\mathrm{g}^{-1}$ ) of the albino maitake specimen. Values are expressed as means \pm standard error, $n=3$.

\begin{tabular}{cc}
\hline Composition/Content & Albino Maitake \\
\hline Nitrogen & $2.18 \pm 0.01$ \\
Proteins & $13.65 \pm 0.00$ \\
Fats & $1.02 \pm 0.04$ \\
Carbohydrates & $6.78 \pm 0.11$ \\
Ash & $1.06 \pm 0.10$ \\
$\mathrm{Ca}$ & $245.30 \pm 0.17$ \\
$\mathrm{Fe}$ & $178.40 \pm 0.15$ \\
$\mathrm{Mg}$ & $455.90 \pm 0.19$ \\
$\mathrm{~K}$ & $11,785.60 \pm 0.36$ \\
$\mathrm{Na}$ & $3433.40 \pm 0.34$ \\
$\mathrm{P}_{2} \mathrm{O}_{5}$ & $2399.61 \pm 0.02$ \\
$\mathrm{Cu}$ & $2.81 \pm 0.02$ \\
$\mathrm{Mn}$ & $2.41 \pm 0.03$ \\
$\mathrm{Zn}$ & $10.33 \pm 0.02$ \\
$\mathrm{Se}$ & $4.00 \pm 0.00$ \\
$\mathrm{~Pb}$ & $2.10 \pm 0.00$ \\
Thiamine $\left(\mathrm{B}_{1}\right)$ & $0.15 \pm 0.03$ \\
Riboflavin $\left(\mathrm{B}_{2}\right)$ & $3.89 \pm 0.06$ \\
Niacin $\left(\mathrm{B}_{3}\right)$ & $0.36 \pm 0.03$ \\
Pantothenic Acid $\left(\mathrm{B}_{5}\right)$ & $0.68 \pm 0.02$ \\
Folic acid $\left(\mathrm{B}_{9}\right)$ & $0.38 \pm 0.01$ \\
$\mathrm{D}_{2}$ & $0.41 \pm 0.02$ \\
\hline
\end{tabular}

The content in vitamins was: $\mathrm{B}_{1}, 0.15 \mathrm{mg} 100 \mathrm{~g}^{-1} ; \mathrm{B}_{2}, 0.36 \mathrm{mg} \cdot 100 \mathrm{~g}^{-1} ; \mathrm{B}_{3}, 3.89 \mathrm{mg} \cdot 100 \mathrm{~g}^{-1} ; \mathrm{B}_{5}$,

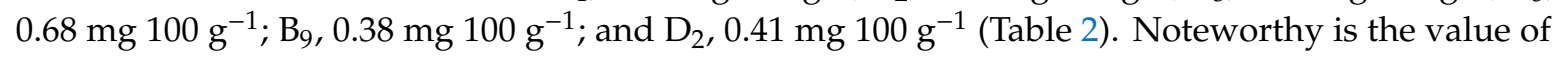
vitamin $B_{9}$, or folic acid, since the daily requirement is about $0.2 \mathrm{mg}$, which doubles for pregnant women [28].

\subsection{Antibacterial and Antibiofilm Activity}

The minimal inhibitory concentration (MIC) of the extract deriving from the albino maitake was determined by a micro-method, i.e., by diluting the protein extract in the range from $25 \%$ to $0.025 \% v / v$ as previously described [29].

The antibacterial activity test carried out on albino maitake showed that the cold water extract was effective in inhibiting the growth of two bacterial strains, i.e., S. epidermidis ATCC 12228 and P. aeruginosa ATCC 15442 , at the maximum screening concentration of $50 \%$ v/v. S. epidermidis is a Gram-positive bacterium typically present on the skin, which could be particularly dangerous in surgical procedures, while $P$. aeruginosa, is a ubiquitous bacterium and opportunistic pathogen in humans. As regards the effect of the water extract from the albino G. frondosa on biofilm formation, the results revealed that it decreased the biofilm produced by S. aureus ATCC43300 [30], whereas it slightly enhanced biofilm formation by E. faecalis ATCC 29212, E. coli ATCC 25922, K. pneumoniae ATCC 700603, and P. aeruginosa ATCC 15442 (Figure 4). 


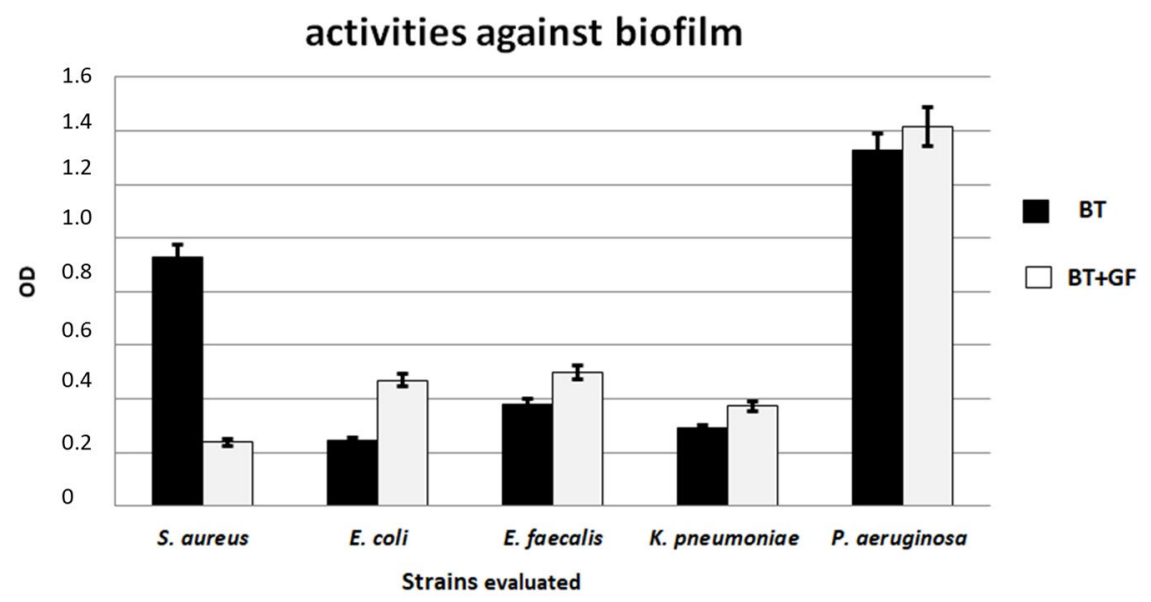

Figure 4. Effect of the cold water extract from the albino Grifola frondosa basidioma on biofilm production (expressed as optical density, OD) by five bacterial species. BT: biofilm produced in the absence of the fungal extract; BT+GF: biofilm produced in the presence of the fungal extract. The experiment was conducted in triplicate.

\subsection{Ecological and Conservation Issues}

The characterization of mushrooms growing in the Mediterranean area is one of the main targets of studies carried out by our research group. The principal objective is to provide reliable/robust scientific data amid the considerable confusion existing in the commercial exploitation of pertinent material in Italy and elsewhere, since accurate identification and/or origin of products placed on the market are often missing or of ambiguous validity. Previous results have highlighted the importance of mushrooms of the genus Pleurotus in human nutrition and in the feeding of farm animals [31-35]. Particular attention is also drawn to edible mushroom species that are infrequent/rare or linked to particular habitats (e.g., Pleurotus nebrodensis and P. opuntiae) [36,37], and for which only few or no studies exist regarding their nutritional and medicinal properties.

Although G. frondosa is widely distributed in the northern hemisphere, it is considered very rare in Italy. Particularly in Sicily, the only reports available concern the brown maitake found in the northeastern part of the island and date back to the end of the 19th century [38]; more recent informal records by amateur mycological groups derive from the same wider region (however, no pertinent samples are available for further study). Hence, the occurrence of an albino maitake is of apparent importance in a biogeographical, ecological, and applied context. In addition, the presence of this fungus on a monumental $Q$. pubescens tree of high significance points out the potential risks for host plants in the area because G. frondosa demonstrates a parasitic action resulting in root and butt decay $[39,40]$. At the same time, it is necessary to ensure the necessary conditions for its ex situ conservation due to the exploitation potential it exhibits as food and source of bioactive compounds as it was reported for wild mushrooms in general [41]. We have therefore adopted well-established protocols for its long-term maintenance [42] since our investigation showed that fructification of the albino maitake is not constant over time and the ability of the strain to be preserved under laboratory conditions-without significant degeneration of its properties-is lower than in other mushroom species.

\section{Conclusions}

An albino maitake specimen was reported for the first time in Italy. The examined basidioma differs morphologically from the common brown/gray form, with the most significant differences being the color and shape of the pileus, the type of pores, the shape of the stipe, and the period of fructification. Phylogenetic analysis evidenced that the specimen under study groups among other European isolates within a larger terminal clade corresponding to G. frondosa. Moreover, the nutritional composition 
and the potential of the albino maitake to serve as source of functional compounds is of interest, and further investigation is in progress on the characterization of polysaccharides and at evaluating the antitumor activity against several types of cancer cells. The outcome of tests performed using the mushroom water extract against human pathogenic bacteria demonstrated its efficacy at inhibiting the growth of S. epidermidis and P. aeruginosa strains, while it also hindered biofilm formation by S. aureus, i.e., the causal agent of serious infections in immunocompromised patients. The antibacterial agents present in the albino maitake are promising candidates for dealing with pathogens that show resistance to a large spectrum of antibiotics and are widespread in hospitals.

Author Contributions: Conceptualization, G.V. and M.L.G.; methodology, G.V., G.I.Z., M.L.G. and O.S.I.; validation, R.C. and V.F.; formal analysis, G.I.Z., M.L.G. and O.S.I.; investigation, G.V., G.I.Z., M.L.G. and O.S.I.; data curation, A.G. and T.F.; biofilm analysis, R.C. and V.F.; writing—original draft preparation, G.V. and M.L.G.; writing-review and editing, G.V. and G.I.Z.; visualization, G.V.; supervision, G.V. All authors have read and agreed to the published version of the manuscript.

Funding: This research received no external funding.

Conflicts of Interest: The authors declare no conflicts of interest.

\section{References}

1. Justo, A.; Miettinen, O.; Floudas, D.; Ortiz-Santana, B.; Sjökvist, E.; Lindner, D.L.; Nakasone, K.; Niemelä, T.; Larsson, K.-H.; Ryvarden, L.; et al. A revised family-level classification of the Polyporales (Basidiomycota). Fungal Biol. 2017, 121, 798-824. [CrossRef] [PubMed]

2. Chen, A.W.; Stamets, P.; Cooper, R.B.; Huang, N.L.; Han, S.-H. Ecology, morphology, and morphogenesis in nature of edible and medicinal mushroom Grifola frondosa (Dicks.: Fr.) S.F. Gray-Maitake (Aphyllophoromycetideae). Int. J. Med. Mushrooms 2000, 2, 8. [CrossRef]

3. Imazeki, R. Genera of Polyporaceae of Nippon. Bull. Nat. Sci. Mus. Tokyo 1943, 6, 1-111.

4. Kawaguchi, N.; Hayashi, M.; Chen, F.-C.; Shimomura, N.; Yamaguchi, T.; Aimi, T. Genetic analyses of causal genes of albinism (white fruiting body) in Grifola frondosa. J. Wood Sci. 2019, 65, 32. [CrossRef]

5. Kawaguchi, N.; Hayashi, M.; Nakano, S.; Shimomura, N.; Yamaguchi, T.; Aimi, T. Expression of tyrosinase genes associated with fruiting body formation and pigmentation in Grifola frondosa. Mycoscience 2019, 60, 262-269. [CrossRef]

6. Gargano, M.L.; Van Griensven, L.J.L.D.; Isikhuemhen, O.S.; Lindequist, U.; Venturella, G.; Wasser, S.P.; Zervakis, G.I. Medicinal mushrooms: Valuable biological resources of high exploitation potential. Plant Biosyst. 2017, 151, 548-565. [CrossRef]

7. Bernicchia, A. Polyporaceae s.l.; Edizioni Candusso: Alassio, Italy, 2005; p. 808.

8. White, T.J.; Bruns, T.; Lee, S.; Taylor, J. Amplification and Direct Sequencing of Fungal Ribosomal RNA Genes for Phylogenetics; Academic Press: Cambridge, MA, USA, 1990; pp. 315-322.

9. Kumar, S.; Stecher, G.; Li, M.; Knyaz, C.; Tamura, K. MEGA X: Molecular evolutionary genetics analysis across computing platforms. Mol. Biol. Evol. 2018, 35, 1547-1549. [CrossRef]

10. Kimura, M. A simple method for estimating evolutionary rates of base substitutions through comparative studies of nucleotide sequences. J. Mol. Evol. 1980, 16, 111-120. [CrossRef]

11. Palazzolo, E.; Gargano, M.L.; Venturella, G. The nutritional composition of selected wild edible mushrooms from Sicily (southern Italy). Int. J. Food Sci. Nutr. 2011, 63, 79-83. [CrossRef]

12. AOAC. Official Methods of Analysis of the AOAC. Anal. Chem. 1980, 52, 148A. [CrossRef]

13. Thompson, T.E.; Senter, S.D.; Grauke, L. Lipid content and fatty acids of pecan pollen. HortScience 1993, 28, 1191-1193. [CrossRef]

14. Loewus, F.A. Improvement in anthrone method for determination of carbohydrates. Anal. Chem. 1952, $24,219$. [CrossRef]

15. Calà, C.; Amodio, E.; Di Carlo, E.; Virruso, R.; Fasciana, T.; Giammanco, A. Biofilm production in Staphylococcus epidermidis strains, isolated from the skin of hospitalized patients: Genetic and phenotypic characteristics. New Microbiol. 2015, 38, 521-529. [PubMed] 
16. Fasciana, T.; Gentile, B.; Aquilina, M.; Ciammaruconi, A.; Mascarella, C.; Anselmo, A.; Fortunato, A.; Fillo, S.; Petralito, G.; Lista, F.; et al. Co-existence of virulence factors and antibiotic resistance in new Klebsiella pneumoniae clones emerging in south of Italy. BMC Infect. Dis. 2019, 19, 928. [CrossRef]

17. Ryvarden, L.; Gilbertson, R.L. European Polypores. Part 1. Synopsis Fungorum 1993, 6, 1-387.

18. Shen, Q.; Geiser, D.M.; Royse, D.J. Molecular Phylogenetic Analysis of Grifola frondosa (Maitake) reveals a species partition separating Eastern North American and Asian Isolates. Mycologia 2002, 94, 472-482. [CrossRef]

19. Stamets, P. Notes on Nutritional properties of culinary-medicinal mushrooms. Int. J. Med. Mushrooms 2005, 7, 103-110. [CrossRef]

20. Niedzielski, P.; Mleczek, M.; Budka, A.; Rzymski, P.; Siwulski, M.; Jasińska, A.; Gąsecka, M.; Budzyńska, S. A screening study of elemental composition in 12 marketable mushroom species accessible in Poland. Eur. Food Res. Technol. 2017, 243, 1759-1771. [CrossRef]

21. Koutrotsios, G.; Mountzouris, K.; Chatzipavlidis, I.; Zervakis, G.I. Bioconversion of lignocellulosic residues by Agrocybe cylindracea and Pleurotus ostreatus mushroom fungi-Assessment of their effect on the final product and spent substrate properties. Food Chem. 2014, 161, 127-135. [CrossRef]

22. Sakellari, A.; Karavoltsos, S.; Tagkouli, D.; Rizou, C.; Sinanoglou, V.J.; Zoumpoulakis, P.; Koutrotsios, G.; Zervakis, G.I.; Kalogeropoulos, N. Trace elements in Pleurotus ostreatus, P. eryngii, and P. nebrodensis Mushrooms Cultivated on various agricultural by-products. Anal. Lett. 2019, 52, 2692-2709. [CrossRef]

23. Garcia, E.M.; Siegert, I.G.; Suarez, P. Toxicity assays and naphthalene utilization by natural bacteria selected in marine environments. Bull. Environ. Contam. Toxicol. 1998, 61, 370-377. [CrossRef] [PubMed]

24. Mendil, D.; Özgür, D.U.; Tuzen, M.; Hasdemir, E.; Sarı, H.; Sari, H. Trace metal levels in mushroom samples from Ordu, Turkey. Food Chem. 2005, 91, 463-467. [CrossRef]

25. Venturella, G.; Gargano, M.L.; Compagno, R.; Saitta, A.; Alaimo, M.G. The mineral contents of some boletaceae species from Sicily (Southern Italy). J. AOAC Int. 2014, 97, 612-623. [CrossRef]

26. Kokkoris, V.; Massas, I.; Polemis, E.; Koutrotsios, G.; Zervakis, G.I. Accumulation of heavy metals by wild edible mushrooms with respect to soil substrates in the Athens metropolitan area (Greece). Sci. Total. Environ. 2019, 685, 280-296. [CrossRef] [PubMed]

27. Fidanza, F. Alimenti e Tabelle di Composizione. In Nutrizione Umana; Fidanza, F., Liguori, G., Eds.; Idelson: Napoli, Italy, 1984; pp. 221-238.

28. Barua, S.; Kuizon, S.; Junaid, M.A. Folic acid supplementation in pregnancy and implications in health and disease. J. Biomed. Sci. 2014, 21, 77. [CrossRef] [PubMed]

29. Schillaci, D.; Petruso, S.; Sciortino, V. 3,4,5,3',5'-Pentabromo-2-(2'-hydroxybenzoyl) pyrrole: A potential lead compound as anti-Gram-positive and anti-biofilm agent. Int. J. Antimicrob. Agents 2005, 25, 338-340. [CrossRef] [PubMed]

30. Giammanco, A.; Galia, E.; Fasciana, T.; Sciortino, M.; Cannella, S.; Arrigo, I.; Tricoli, M.R.; Di Paola, L.; Venturella, G.; Gargano, M.L. The Anti-Biofilm Potential of Pleurotus eryngii var. elaeoselini and White form of Grifola frondosa Extracts Against Staphylococcus aureus methicillin Resistance. In Proceedings of the 10th International Medicinal Mushrooms Conference, Nantong, China, 19-22 September 2019; International Society for Medicinal Mushrooms \& Jiangsu Provincial Department of Agriculture and Rural Affairs: Nantong, China, 2019; pp. 184-185.

31. La Guardia, M.; Venturella, G.; Venturella, F. On the chemical composition and nutritional value of Pleurotus taxa growing on Umbelliferous plants (Apiaceae). J. Agric. Food Chem. 2005, 53, 5997-6002. [CrossRef] [PubMed]

32. Koutrotsios, G.; Kalogeropoulos, N.; Stathopoulos, P.; Kaliora, A.C.; Zervakis, G.I. Bioactive compounds and antioxidant activity exhibit high intraspecific variability in Pleurotus ostreatus mushrooms and correlate well with cultivation performance parameters. World J. Microbiol. Biotechnol. 2017, 33, 98. [CrossRef]

33. Koutrotsios, G.; Kalogeropoulos, N.; Kaliora, A.C.; Zervakis, G.I. Toward an Increased functionality in oyster (Pleurotus) mushrooms produced on Grape Marc or Olive Mill Wastes Serving as sources of bioactive compounds. J. Agric. Food Chem. 2018, 66, 5971-5983. [CrossRef]

34. Gaglio, R.; Guarcello, R.; Venturella, G.; Palazzolo, E.; Francesca, N.; Moschetti, G.; Settanni, L.; Saporita, P.; Gargano, M.L. Microbiological, chemical and sensory aspects of bread supplemented with different percentages of the culinary mushroom Pleurotus eryngii in powder form. Int. J. Food Sci. Technol. 2018, 54, 1197-1205. [CrossRef] 
35. Bonanno, A.; Di Grigoli, A.; Vitale, F.; Di Miceli, G.; Todaro, M.; Alabiso, M.; Gargano, M.L.; Venturella, G.; Anike, F.N.; Isikhuemhen, O.S. Effects of diets supplemented with medicinal mushroom myceliated grains on some production, health, and oxidation traits of dairy ewes. Int. J. Med. Mushrooms 2019, 21, 89-103. [CrossRef]

36. Zervakis, G.I.; Ntougias, S.; Gargano, M.L.; Besi, M.I.; Polemis, E.; Typas, M.A.; Venturella, G. A reappraisal of the Pleurotus eryngii complex-New species and taxonomic combinations based on the application of a polyphasic approach, and an identification key to Pleurotus taxa associated with Apiaceae plants. Fungal Biol. 2014, 118, 814-834. [CrossRef] [PubMed]

37. Zervakis, G.I.; Venturella, G.; Fryssouli, V.; Inglese, P.; Polemis, E.; Gargano, M.L. Pleurotus opuntiae revisited-An insight to the phylogeny of dimitic Pleurotus species with emphasis on the P. djamor complex. Fungal Biol. 2019, 123, 188-199. [CrossRef] [PubMed]

38. Venturella, G. A check-list of Sicilian fungi. Bocconea 1991, 2, 1-221.

39. Antonio, A.; Valeria, B.; Marcello, D.; Caterina Patrizia Di, F.; Di Gesaro, M.; Emanuele, S. Monumental trees and their existence value: The case study of an Italian natural park. J. For. Sci. 2016, 61, 55-61. [CrossRef]

40. Schwarze, F.W.M.R.; Engels, J.; Mattheck, C. Fungal Strategies of Wood Decay in Trees; Springer: Berlin/Heidelberg, Germany, 2000.

41. Zotti, M.; Persiani, A.M.; Ambrosio, E.; Vizzini, A.; Venturella, G.; Donnini, D.; Angelini, P.; Di Piazza, S.; Pavarino, M.; Lunghini, D.; et al. Macrofungi as ecosystem resources: Conservation versus exploitation. Plant Biosyst. 2013, 147, 219-225. [CrossRef]

42. Moore, D.; Nauta, M.M.; Evans, S.E.; Rotheroe, M. Fungal Conservation. Issues and Solutions; Cambridge University Press: Cambridge, UK, 2001; p. 262.

(C) 2020 by the authors. Licensee MDPI, Basel, Switzerland. This article is an open access article distributed under the terms and conditions of the Creative Commons Attribution (CC BY) license (http://creativecommons.org/licenses/by/4.0/). 